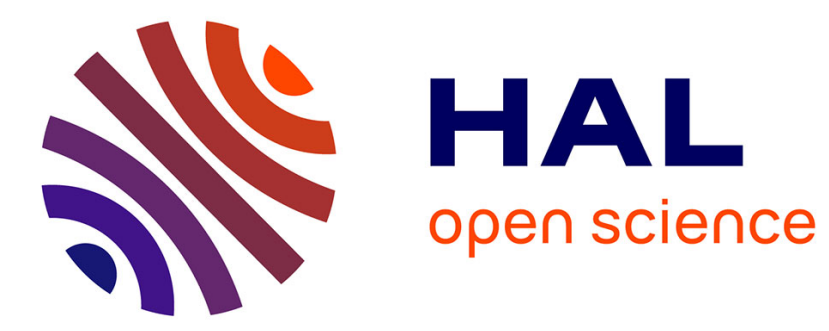

\title{
On the semantic and contextual factors that determine topic selection in Italian and Spanish
}

\author{
Lisa Brunetti
}

\section{To cite this version:}

Lisa Brunetti. On the semantic and contextual factors that determine topic selection in Italian and Spanish. Linguistic Review, 2009, 26 (2-3), pp.261 - 289. 10.1515/tlir.2009.010 . hal-01831607

\section{HAL Id: hal-01831607 \\ https://hal.science/hal-01831607}

Submitted on 6 Jul 2018

HAL is a multi-disciplinary open access archive for the deposit and dissemination of scientific research documents, whether they are published or not. The documents may come from teaching and research institutions in France or abroad, or from public or private research centers.
L'archive ouverte pluridisciplinaire HAL, est destinée au dépôt et à la diffusion de documents scientifiques de niveau recherche, publiés ou non, émanant des établissements d'enseignement et de recherche français ou étrangers, des laboratoires publics ou privés. 


\title{
On the semantic and contextual factors that determine topic selection in Italian
}

\author{
and Spanish ${ }^{1}$
}

Lisa Brunetti, Universitat Pompeu Fabra

\section{Introduction}

Consider the Italian (left) and Spanish (right) sentences below:

(1) a. La segretaria ha spedito la lettera. / La secretaria envió la carta. the secretary has mailed the letter the secretary mailed the letter 'The secretary mailed the letter'

b. A Gianni piacciono i film dell'orrore. / A Juan le gustan las películas de horror. to G. please the movies of-the horror to J. to-him $\mathrm{cl}_{\mathrm{cl}}$ please the movies of horror 'Gianni/Juan likes horror movies

c. La lettera, l'ha spedita la segretaria. / La carta, la envió la secretaria. the letter $\mathrm{it}_{\mathrm{cl}}$ has mailed the secretary the letter $\mathrm{it}_{\mathrm{cl}}$ mailed the secretary 'As for the letter, the SECRETARY mailed it'

In (1a), the preverbal element is a subject, in (1b) it is an Indirect Object (from now on, IO), and in (1c) it is a Direct Object (from now on, DO). The IO in (2) is obligatorily resumed by a clitic in Spanish, optionally in Italian. In (1c), the DO is obligatorily resumed by a clitic both in Spanish and in Italian. I will call the latter construction (Clitic) Left Dislocation (from now on: (CL)LD). When these sentences are uttered with a normal, descending intonation, the preverbal elements represent the sentence topic. In this article, I will discuss the semantic and contextual reasons for a certain argument to be "promoted" to a topic position. Whenever it is crucial to distinguish the pragmatic

\footnotetext{
${ }^{1}$ I thank the two anonymous reviewers and the editors for useful comments and suggestions. I also thank Enric Vallduví, Álex Alsina, and Louise McNally for useful discussion, and the participants of the workshop "What's the topic?" at the Radboud Universiteit Nijmegen (Jan. 23-24, 2007) for their comments and questions. I take responsibility for all remaining errors. This article was supported by the Spanish Ministry of Education through the Juan de la Cierva postdoctoral fellowship.
} 
concept of topic from its linguistic realization, I will use the words "topic expression" to refer to the linguistic entity. ${ }^{2}$

This article is organized as follows. In Section 2, I present the pragmatic and syntactic characteristics of topic expressions. In Section 3, I discuss the common overlapping between subject and topic and propose that both tend to have agent-like properties. I argue that for topics, that tendency is due to the fact that agent-like properties are a semantic reflex of the cognitive characteristics that define a prototypical topic, while for subjects it depends on argument selection rules. In Section 4, I present the notion of canonical and non-canonical sentences: the former have a prototypical topic, the latter do not. I illustrate cases of canonical and non canonical sentences with non-subject topics. The former are found with psychological, unaccusative, impersonal verbs, with passives, and with clauses that have an arbitrary subject. The latter are found in contrastive contexts. I argue in fact that the requirement to have a prototypical topic is overruled in that particular contextual situation. In Section 5, conclusions are drawn.

\section{Characteristics of topic expressions: pragmatics and syntax}

Following the tradition of Strawson (1964), Kuno (1972), Reinhart (1981), Lambrecht (1994), and many others, I assume that a sentence topic is "what the sentence is about". More precisely, adopting Vallduví's definition, a topic expression (a link, in his terminology) directs "the hearer to a given address (...) in the hearer's knowledge store, under which the information carried by the sentence is entered" (Vallduví 1992:59). This definition highlights the anchoring role of the topic to the common ground. Additionally, it points out the updating function of a topic expression. In fact, the

\footnotetext{
${ }^{2}$ For a discussion about this distinction, see McNally (1998).
} 
operation of directing the hearer to an address implies that a different topic is introduced in the discourse whenever such an operation takes place (in other words, a topic shift occurs). So summarizing, in this article I assume that a topic expression always represents an aboutness and shifting topic. ${ }^{3}$

As for the syntactic position, the literature is divided with respect to two issues. One issue is whether subject topics are dislocated (but without clitic resumption, as these languages do not have subject clitics), or rather they stay in their canonical, spec,IP position. The question depends on the position in which subjects are assumed to be based-generated. For instance, according to Vallduví (1993), subjects in Catalan are base-generated in a post-verbal position; therefore, their preverbal manifestations are always the result of movement to an adjoined-to-IP position. Because of this analysis, É. Kiss (1995) considers Catalan as a "topic prominent language", namely a language whose sentence structure gives a major role to the grammatical relation topic-comment (Li and Thompson 1976). It is not clear whether Spanish and Italian are topic prominent languages too, and I will not deal with this issue in the present article. Keeping my syntactic assumptions to a minimum, I will limit myself to say that preverbal, sentence initial arguments in sentences with a neutral, descending intonation are topics (cf. Benincà 1988[2001]:144, Salvi 1988[2001]:53, Zubizarreta 1999).

The other issue concerns the contrastive interpretation of topics. It has been claimed in the literature (see Belletti and Rizzi 1988 for Italian; Masullo 1993 and FernandezSoriano 1999 for Spanish; among others) that the IO of an object-experiencer psychological verb (cf. 1b) occupies a different position than a (CL)LD (cf. the DO in (1c)). While the latter is a case of movement to a position in the $\mathrm{C}$ (omplementizer) area,

\footnotetext{
${ }^{3}$ See Brunetti (in press-a) for evidence in Italian that a topic expression always indicates a topic shift.
} 
the former occupies a lower position (e.g., the low C position Fin, Frey 2004). Within that approach, contrast, which is present with a CLLD but not with a IO, is a consequence of the syntactic difference between the two constructions. In this article, I derive the contrastive interpretation of the DO from the fact that a DO is generally a 'bad topic' from a thematic point of view, and so it is used as topic only in specific contexts, namely contrastive ones. Without excluding that the DO in (1c) and the IO in (1b) may occupy two different positions in the syntactic tree, the reason for this difference does not have to do with contrast, but rather is related to syntactic constraints on movement of different arguments.

\section{Subjects, topics, and agents}

If we look at corpus data in the languages under discussion, we see that subjects are much more frequently preverbal than other arguments. It follows that subjects represent the sentence topic much more often than other arguments. ${ }^{4}$ The relation between topic and subject has been frequently noticed in the literature. Reinhart (1981:62) observes that there is a strong preference in English to interpret the grammatical subject as the sentence topic and to place the topic in subject position. Chafe (1976), Prince (1992), Lambrecht (1994), among many others, observe that most subjects have topic properties (familiarity, definiteness, "aboutness"). Why are subjects good topics? According to Lambrecht (1994), "since the subject is the most common argument in the sentence most predicates have at least a subject but not necessarily an object complement - it is

\footnotetext{
${ }^{4}$ A preverbal subject can also be considered as part of a fully focused sentence. However, I assume that whenever the verb is preceded by an argument in Italian and Spanish, that argument is automatically interpreted as topic (with a descending intonation). It might be the case, though, that while non-subject topics are always shifting, subject topics can be continuous. Cf. Duranti and Ochs (1979).
} 
necessarily also the argument which will be most readily identified with the pragmatic role of topic" (Lambrecht 1994:132). I believe that this reasoning is not sufficient to explain why subjects are good topics. The fact that a verb selects just one argument - the subject - does not automatically give it a topic status. As Lambrecht himself observes and discusses in detail, and as we will see below, subjects of unaccusative monovalent verbs are usually not chosen as topics. Furthermore, the fact that the subject is the most common argument among verbs does not explain why, when a verb selects more than one argument, the preferred topic is the subject.

In this article, I propose that a subject is usually chosen as topic because topics and subjects tend to be associated with similar thematic properties. It is a well-known fact in the literature on accusative languages that subjects in active clauses, cross-linguistically and cross-verbally, tend to be agents (van Oosten 1986; Dowty 1991; Lambrecht 1994, 1995, Primus 1999; among others). The relation between topichood and agentivity has been noticed too (van Oosten 1986; Lambrecht 1994; Primus 1999; Lamers and de Hoop 2005; among others). In other words, there is a correspondence among topichood, subjecthood and agentivity (cf. Lambrecht 1995; Murcia-Serra 2003). In Lambrecht's view, agent topics are simply a result of the fact that topics are generally subjects and subjects are generally agents. The correlation between topichood and subjecthood is more basic than that between topichood and agentivity. My view on the contrary is that the subject-topic relation is derived, namely it is a consequence of the fact that a good topic is an agent, and agents are given the grammatical status of subjects. This position explains why, in the constructions to be discussed in Section 4.2, the subject is a less appropriate topic. We will see that when a subject does not have "enough" agent-like properties, the topic position is occupied by a different argument. If topics tended to be 
subjects and the topic-agent relation was derived, topics would still be subjects in sentences where the subject is not agent; on the contrary, precisely in those circumstances, a different argument is chosen. Furthermore, the relation between topics and agents is not arbitrary, but rather is based on the idea that, from a cognitive point of view, a topic is more likely to be instantiated by a participant in the event with agentlike properties than by a participant with a different role (see van Oosten 1986; Givón 1976, 1994; Mac Whinney 1977; and others).

Summarizing, my point is that subjects and topics tend both to be agents, but they do it for different reasons. Subjects are agents because, according to argument selection rules (see Subsection 3.2), if a verb requires an agent, it assigns it the grammatical function of subject. Topics, on the contrary, are agents because agentivity is more likely to be associated with topichood (it is a prototypical property of topics) given the notion of topichood adopted in this article (that is, speakers prefer to talk about agents). While the operation of choosing a subject is done at a lexical level, that of choosing a topic is done at the utterance level, and the overlapping of subject and topic is simply accidental (at least at a synchronic level of the language, see Givón 1976), and it may not occur in the eventuality that argument selection rules and factors determining the choice of topic do not end up selecting the same argument. Indeed, we will see that with some specific verbs or constructions, the overlapping does not occur. In this sense, my proposal is less strong than the one given by Givón (1976). Givón uses topic prototypicality to explain syntactic constructions such as existential sentences or morphological phenomena such as agreement. In this article, I only explain word order preferences in discourse. This is possible, because the languages under study have a relatively free word order, namely 
not driven by syntactic constraints and therefore usable for the organization of discourse. $^{5,6}$

\subsection{Topic-agent relation: prototypical topic}

In this Subsection I will present the properties that scholars have singled out for a topic to be prototypical, and the reasons why such properties make it prototypical.

Specifically, I will argue for the fact that agentivity is a prototypical topic property.

Some scholars have proposed a hierarchy of topicality, namely of likelihood of an argument to be sentence topic. Givón $(1976,1994)$ splits the hierarchy into subhierarchies, some of which are reported below. ${ }^{7}$ From left to right, the referent of the argument chosen as topic preferably is:

(2) a. speaker $>$ hearer $>$ 3rd person

b. human $>$ animate $>$ inanimate

c. agent $>$ dative $^{8}>$ patient

d. large $>$ small

e. possessor $>$ possessed

f. definite $>$ indefinite

\footnotetext{
${ }^{5}$ Optional movement is a syntax-driven phenomenon for those who argue for syntactic features for pragmatic categories (in that approach, optionality is accounted for by covert movement). I do not follow that kind of approach. For extensive arguments against it, see Brunetti (2004, in press-b).

${ }^{6}$ Whether the choice of a particular word order in languages that allow for optionality is driven exclusively by pragmatic preferences (as I claim for Italian and Spanish) or is also driven by syntactic preferences (e.g., of a subject first, cf. Dutch) can only be seen through a quantitative investigatgion on a large corpus. Such a work, however, goes beyond the limits and scope of the present article.

${ }^{7}$ Duranti and Ochs (1979) provide some evidence that these hierarchies apply to left-dislocated elements (that is topics) in Italian.

${ }^{8}$ I believe that Givón means a thematic role such as experiencer or beneficiary, which are typically realized with dative case.
} 
These hierarchies are motivated by humans' preference to speak about certain topics rather than others, and their tendency to view things (and talk about them) from a certain perspective. The preference in (2a) and (2b) are explained by Givón by appealing to the "ego/anthropocentric nature of discourse" (Givón 1976:152), namely the tendency of humans to speak about themselves or what is similar to themselves (cf. also Zubin 1979; Kuno 1976). (2a) is also motivated by the fact that speaker and hearer are highly salient in the discourse, and topics, given their anchoring role (cf. Vallduví 1992), have to be given or at least be part of the interlocutors' common ground. A similar explanation holds for (2f), as definite expressions are existentially presupposed and therefore already present in the minds of the interlocutors. (2c) is motivated by the tendency of speakers to tell an event from the perspective of the participant that is more involved in it and that has more control over it. Preferences such as (2d) and (2e) can also be explained by the preference to talk about an entity with a potentially greater power or capacity to affect an event.

van Oosten (1986) assigns similar properties to what she calls a prototypical topic. She more explicitly ties such properties to general cognitive preferences of humans to talk about certain things and not others. She says in particular that the semantic properties of a prototypical topic expression are a reflex of the fact that :

(3) a. A prototypical topic refers to the speaker and hearer's focus of attention;

b. A prototypical topic preferably is a concrete and visible entity; c. A prototypical topic is a basic level topic.

From the property in (3a) it follows that a prototypical topic is already part of the common ground. As seen above in Givón's classification, the preference to talk about 
what is already part of the common ground explains the preference for definite topic expressions. The "ego/anthropocentric nature of discourse" makes the speaker's normal focus of attention to be an entity that resembles the speaker as much as possible, so the topic is preferably human or animate (cf. (2b)). Furthermore, since "agents are cognitively salient to humans" (van Osten 1986:30), a prototypical topic expression is expected to be an agent (cf. (2c)). The property in (3b) is linguistically reflected by the fact that a prototypical topic expression is referential. Point (3d), finally, refers to van Oosten's classification of (discourse) topics in three "layers": superordinate topic, basiclevel topic, and subordinate topic. A superordinate topic represents the set of experience, knowledge, memories, judgments that are needed to interpret a specific language text (what van Oosten calls a 'cognitive schema', and other scholars call 'scene' or 'frame'; see references in van Oosten 1986:42, footnote 5). A basic-level topic is instead a participant or an element inside the 'scene' (the superordinate topic), and a subordinate topic is an aspect or a part of a participant or an object (the basic-level topic). van Oosten's claim is that at sentence level, the preferred topics are the participants in a scene, namely basic-level topics. Among the participants in a scene, major participants are more prototypical than minor participants, and humans are more prototypical than inanimate objects. Speakers prefer to talk about the main characters in a scene, and secondarily about other participants in the scene, or about relevant objects in the scene. Speakers tend to prefer all these topics to abstract objects like events or scenes themselves (superordinate topics). ${ }^{9}$ On the other hand, speakers prefer to talk about individuals or objects rather than aspects or parts of them (subordinate topics).

\footnotetext{
${ }^{9}$ An analogous preference, pointed out by MacWhinney (1977), is for humans to use figures than grounds as 'starting point' (a notion that is clause to that of topic, see Duranti and Ochs 1979).
} 
As a final remark on the topic-agent relation, I would like to point out that since it is determined by what speakers prefer to talk about, I assume it to hold for all languages. For accusative languages, that relation is indeed strongly attested, while in ergative languages, its existence is less clear. As pointed out by Primus (1999) (who makes similar assumptions on the topic-agent relation) it is commonly believed that in ergative languages, patients and not agents represent the unmarked topic. Since I am focusing on two accusative languages, I will not tackle the issue of ergative languages in this article. I would like however to report Primus's remark that the claim on patient topics in ergative languages has been challenged by many scholars in the literature. I refer the reader to Primus (1999:175) for references and a more detailed discussion.

\subsection{Subject-agent relation: argument selection rules}

I have said above that the relation between subject and agent is of a different nature than that between topic and agent: it is in fact determined by lexical rules of argument selection. I am going to present now Dowty's (1991) proposal, namely his Principle of Argument Selection. Dowty's principle is part of a more general proposal concerning thematic roles, which I will summarize below. My analysis of non-subject topics given in Section 4 will be based on that proposal.

Dowty (1991) proposes that thematic roles are not discrete categories but rather a cluster of concepts. Verbs impose lexical entailments on their arguments, which can be divided into two groups: those that express agent-like properties (forming together a 'Proto-Agent role'), and those that express patient-like properties (forming a 'Proto- 
Patient role'). Thematic roles are thus not primitives, but rather derived notions. ${ }^{10}$ The entailments forming the Proto-Agent role are:

(4) Proto-Agent role: (a) Volitional involvement; (b) Sentience or Perception; (c) Cause of a change of state in another participant; (d) Movement relative to another participant (Water filled the boat); (e) Existence independent of the event.

The entailments that form a Proto-Patient role are almost complementary:

(5) Proto-PATIENT role: (a) Change of state; (b) Incremental Theme (John filled the glass with water); (c) Being causally affected; (d) Being stationary relative to another participant; (e) Existence not independent of the event.

The number of entailments that a verb imposes on each of its arguments may vary from none to all. Besides, an argument may be assigned both proto-agent and proto-patient entailments.

Primus (1999) makes some revisions to (4) and (5). Instead of "volition", she talks about "control", to underline the fact that an agent is not just the individual who has the intention to do something, but more generally who has a control over the event. ${ }^{11}$ Furthermore, Primus makes it more precise in what sense movement (see $4 \mathrm{~d}$ ) is a protoagent entailment. It is not intended as movement caused by another participant (which is, rather, a proto-patient property) but movement as an "autonomous activity". In this sense, (5d) must also be revised to include participants that are causally moved by another participant. Vanhoe (2002) proposes a further revision: he substitutes

\footnotetext{
${ }^{10} \mathrm{Cf}$. the macro-roles of Van Valin (1990 and related works).

${ }^{11}$ A similar notion of "control" is used by Kline and Perdue (1992) to explain word order preferences of L2 speakers. They say that speakers at early stages of (spontaneous) acquisition of a foreign language tend to utter the NP-referent first that has the highest control on the other referents in the event. Kline and Perdue also say that at the two-word level, speakers tend to utter topic material first and focus material last. It follows that among these speakers, controller and topic tend to coincide.
} 
independently/dependently existing from the event with container/contained and possessor/possessed. Along the same lines, Primus points out that what all proto-patient properties have in common is thematic dependence on another participant. More generally, Agent and Patient proto-roles are distinguished by their dependency relative to each other (see also Levin and Rappaport Hovav 2005:63, and references quoted there). ${ }^{12}$

According to Dowty, the distribution of entailments determines argument selection. Dowty's Argument Selection Principle is reported (in a shortened version) below:

(6) Argument Selection Principle (Dowty 1991): In predicates with grammatical subject and object, the argument with the greatest number of Proto-Agent properties will be lexicalized as the subject; the argument with the greatest number of Proto-Patient properties will be lexicalized as the DO. ${ }^{13}$

Two corollaries further specify how argument selection works. Cor. 1 establishes that if two arguments have equal numbers of proto-agent and proto-patient properties, either or both may be lexicalized as the subject. Cor. 2 states that with a three-place predicate, the non-subject argument with greater number of proto-patient properties is lexicalized as the DO and the non-subject argument with fewer proto-patient properties is lexicalized as an oblique object.

"Highly" or "primary" transitive verbs (see Hopper and Thompson 1980), such as build, write, murder, eat, wash, etc., perfectly exemplify the prototypical case, where the DO has only proto-patient properties and the subject has only proto-agent properties. Other verbs impose the same number of proto-agent or proto-patient entailments on

\footnotetext{
12 As discussed in Vanoe (2002) and Primus (1999), among others, proto-role properties can also derive from aspectual characteristics of the verb. I will leave this factor aside in this article.

${ }^{13}$ For this generalization, see also Alsina (1996:36) and references quoted there.
} 
their arguments, or impose both proto-agent and proto-patient entailments on the same argument. In the following Section, the consequences of these distributions of entailments on the choice of topic are discussed.

\section{Canonical vs non-canonical sentences}

Assuming Dowty's proto-role theory and given what we said above about prototypical topics, a prototypical topic is expected to have as much proto-agent properties as possible, and more than those of the other arguments. Animacy, control over the event or power to affect the event, etc., are all characteristics of what speakers prefer to talk about. With a transitive verb like (1a), the choice of the subject as topic is uncontroversial, because it has (at least) the proto-agent properties of causation, volition/control, and sentience, while the DO clearly has proto-patient properties. The IO in (1b) is a good topic as well. In fact, it has more proto-agent properties than the subject, as we will see in details in Subsection 4.1, where certain classes of verbs and constructions displaying this thematic pattern will be presented. On the contrary, the DO topic in (1c) is not the most prototypical, because it has proto-patient properties and the post-verbal subject has proto-agent properties. In a parallel fashion, the subject topics in (7) (which correspond to (1b) with reversed order of the arguments), are also not optimal.

(7) I film dell'orrore piacciono a Gianni. / Las películas de horror le gustan a Juan. the movies of-the horror please to Gianni the movies of horror to-him $\mathrm{cl}_{\mathrm{cl}}$ please to Juan

'Gianni/Juan likes horror movies'

I will call canonical those sentences that have a 'good' topic, like (1a) and (1b), and non-canonical those with a 'bad' topic, such as (1c) and (7). Canonicity is determined by the proximity of their topic to the prototype. 
Why should non-canonical orders exist at all? The argument order in (1c) and in (7) is not justified by prototypical properties, so it must be justified by something else. Given that information structure (the articulation of the sentence into topic and focus) is affected and affects discourse structure, it is natural to think that the reason for noncanonical order is a discourse requirement. In fact, my idea is that the choice of topic must always be coherent with discourse needs, so the choice of the most prototypical topic in the sentence is done by the speaker only if the discourse context leaves freedom of choice and does not impose a particular topic. When the context requires a certain argument as topic, it does not matter if that topic is prototypical or not. Within this light, the main difference between canonical and non-canonical sentences is the following: a canonical sentence is not restricted to a particular contextual situation, so it may occur in any kind of context, while a non-canonical sentence, given the non-prototypical characteristics of the topic, can only occur in a particular context.

I will now present data of non-subject topics in constructions that are either canonical or non canonical. Most data are taken from the Nocando corpus, a corpus of oral narrations that I have compiled for the project Nocando: Noncanonical constructions in oral speech at the University of Pompeu Fabra. ${ }^{14}$ Subjects were asked to tell the story depicted in three of Mercer Mayer's textless books (cf. Berman and Slobin 1994; Strömqvist and Verhoven 2004). The Italian corpus is made of 43 narrations by 16 native-speakers, for at total of about 4 hours of speech and about 26,000 words. The Spanish corpus is made of 39 narrations by 13 native-speakers, for a total of about $2 \frac{1 / 2}{2}$ hours of speech and about 23,000 words. Speakers were mostly university students.

\footnotetext{
${ }^{14}$ The project was funded by the Spanish Secretaria de Estado de Universidades e Investigación del Ministerio de Educación y Ciencia, n. I+D HUM2004-04463.
} 
I found a total of 40 non-subject topics in the data (17 in Italian and 23 in Spanish). Canonical sentences, namely those with a prototypical topic, were 9 in Italian and 15 in Spanish. Non-canonical sentences were 8 in Italian and 8 in Spanish. I will first look at canonical sentences, and classify them according to what verb class or construction triggers a prototypical non-subject topic.

\subsection{Canonical sentences with non-subject topics}

Canonical sentences with a non-subject topic are found with verbs that select a nonagent subject and an IO that has proto-agent properties except volition/control, namely an experiencer, a beneficiary, or a possessor. These verbs are (object-experiencer) psychological verbs (see 4.1.1.) and unaccusative verbs (see 4.1.2.). A subject-IO pattern, where the IO is more prototypical than the subject, is also found with passive verbs (see 4.1.3.), and with verbs that lack an overtly expressed subject (impersonal verbs and verbs with an arbitrary subject, see 4.1.4.).

\subsubsection{Object-Experiencer Psychological verbs. Psych(ological) verbs denote a mental} state and select two arguments: one representing the cause of the mental state, and one representing the individual who experiences the mental state. ${ }^{15}$ According to Dowty, the fact that both arguments have one proto-agent property leaves space to alternation, cross-linguistically and within a language, between a subject experiencer (SE) and an object experiencer $(\mathrm{OE})$. The reason for the alternation is that each argument has one proto-agent entailment (cf. Cor. 1), namely causation and sentience respectively.

\footnotetext{
${ }^{15}$ In fact, what I say in this subsection also holds for verbs denoting a physical state, such as the Spanish hacer daño 'to hurt'.
} 
Italian and Spanish have both SE verbs like odiare (It.) /odiar (Sp.) 'to hate' or amare (It.) /querer (Sp.) 'to love', and OE verbs like piacere (Ital.)/gustar (Sp.) 'to please'. Most canonical sentences with non-subject topic in my corpus contain OE psych-verbs: 7 out of 9 in Italian and 9 out of 15 in Spanish. An example is (8):

(8) Ma alla rana piace molto l'acqua. Italian, Noc but to-the frog is-pleasing much the water 'But the frog likes the water very much'

As noted in the literature (cf. Benincà 1988[2001] for Italian), the most natural order is when the IO occupies a preverbal position and the subject is post-verbal, while the reversed order is marked. "Marked" means that the contexts in which the sentence can occur are very few. In other words, the sentence is pragmatically marked. For instance, a sentence like (7) only occurs in contexts where a set of films are compared with respect to their being preferred by a set of individuals; the corresponding sentence with reversed order in (1b), instead, can occur in "out of the blue" contexts, where no set of individuals or films is presupposed.

The pragmatic markedness of the Sbj-Verb-IO order shows that the proto-agent property of causation is less prototypical than that of sentience. Why should that be so? I said above that humans' focus of interest is as much like themselves as possible, so being human or animate is an important characteristic of the topic prototype. While sentience entails that the referent of the argument be animate, causation does not. The pragmatic markedness of a Sbj-V-IO order then indicates that a proto-agent property that involves animacy (such as sentience, volition/control, possession) is more important with respect to the choice of topic than one that does not, such as causation.

The fact that sentience entails animacy is evident when both arguments refer to human beings. While Cesare in (9) must be animate in order to experience a mental 
state of liking, Anna does not need to be aware of the effect she cuases on Cesare in order to cause it. As Dowty points out, "sentience means more than a presupposition that an argument is a sentient being; it is rather sentience with respect to the event or state denoted by the verb" (Dowty 1991:573).

(9) A Cesare piace Anna. I Inna piace a Cesare.

Italian

to Cesare is-pleasing Anna Anna is-pleasing to Cesare

'Cesare likes Anna'

Consider also the psych-verb dare fastidio (It.) / molestar (Sp.) 'to bother, to annoy, to harass'. When the cause of the mental state is inanimate, the preferred word order is with the experiencer in sentence initial position. When both arguments are animate, the verb meaning becomes ambiguous: it can either entail that the individual causing the event does it intentionally or not.

a. Quell'uomo dava fastidio a Maria. Italian that man gave bother to Maria 'That man was harassing Maria' / 'That man bothered Maria' b. A Maria dava fastidio quell'uomo. to Maria gave bother that man 'Maria was harassed by that man' / 'Maria was bothered by that man'

The ambiguity is due to the fact that the verb can impose an additional entailment to the subject: Volition/Control, which makes the cause of the bother intentional). Sentence (10a) is most naturally found in contexts where the interpretation is that the man is voluntarily giving bother to Maria (he is harassing her), and sentence (10b) is found in contexts where the interpretation is that the man is an involuntary cause of Maria's bother. In other words, in (10a) the verb is preferably interpreted as assigning two proto-agent properties to the topic argument and one proto-agent property plus one proto-patient property to the non-topic argument. In (10b), the most natural interpretation is one where the topic has the property of sentience and the non-topic is 
the cause. So the natural interpretation of (10a) is the one where the topic has a larger number of proto-agent properties, and the natural interpretation of (10b), as discussed above, is the one where the topic is sentient, because sentience is a more prototypical property than causation (given the animacy requirement of sentience). ${ }^{16}$

Similar ambiguity of meaning is found in the corresponding Spanish verb molestar, as shown by Ackerman and Moore (2001). In terms of argument selection, many scholars have observed that if the meaning is 'to bother', the experiencer is realized as a DO; if the meaning is 'to harass', it is realized as an IO (see Treviño 1992). This fact shows that in Spanish the two sets of thematic properties also influence argument selection: the ambiguity of the verb is expressed morphologically by the direct-indirect alternation of the object.

4.1.2. Unaccusative verbs. Unaccusative verbs select a subject with proto-patient properties. Some verbs additionally select another argument with some proto-agent properties but not volition/control. Consider (11), with the verb rompersi 'to break' that has reflexive morphology.

(11) A Gianni si è rotto il televisore. Italian to Gianni refl $\mathrm{cl}_{\mathrm{cl}}$ is broken the TV-set 'Gianni's TV set broke'

\footnotetext{
${ }^{16}$ Ackerman and Moore's (2001) analysis of the corresponding Spanish verb molestar is different: they argue that the verb assigns the additional proto-patient property change of state to the object, and no additional proto-agent property to the subject. The result in terms of topic selection is the same: the protopatient property makes the object a worse topic than the subject. However, it is not clear to me in what sense the experiencer undergoes a change of state with one meaning but not with the other. The property of volition/control, on the contrary, clearly highlights the fact that with one meaning, the individual is aware to cause the mental state, and with the other meaning, s/he is not.
} 
Dowty's Principle in (6) cannot predict the selection arguments of this verb. The verb selects a subject referring to an entity that undergoes a change of state (from not-broken to broken), which is a proto-patient entailment. The referent of the IO, on the contrary, is the possessor of the TV set, as the English translation confirms, and the TV set is the possessed entity. We know that being a possessor is a proto-agent property, and being possessed is a proto-patient property. According to (6), the subject should have more proto-agent properties, while in this example it is not the case. Consider, however, that the verb has a transitive counterpart that selects three arguments: the two above, plus an argument with the proto-agent property of volition/control:

(12) Maria ha rotto il televisore a Gianni. Italian Maria has broken the TV-set to Gianni 'Maria broke Gianni's TV set'

The changes in terms of grammatical functions that occur from (12) to (11) are like those that occur from (12) to its passive counterpart, given in (13).

(13) A Gianni è stato rotto il televisore (da Maria). Italian to Gianni is been broken the TV-set by Maria 'Gianni's TV set was broken by Maria'

In both (11) and (13), the subject corresponds to the DO of the transitive counterpart, and the volitional agent is eliminated (with just one difference: (11) describes an event where there is no volitional agent, as nobody caused the TV set to be broken; in (13), its existence is still implied). The problem of (11) for Dowty's theory is therefore analogous to the problem that such theory has with passives. But as Ackerman and Moore (2001) observe, the fact that passives cannot be accounted for in Dowty's theory is expected: alternations of this kind are the result of purely morpho-syntactic manipulations and cannot (must not) be explained by a linking theory of semantic 
entailments with grammatical functions. Therefore, if we assume that (11) can be analyzed as (13), and if we do not attempt to explain why in these constructions the proto-patient is realized as subject, Dowty's Principle can predict the realization as IO of the argument with proto-agent properties. That argument could not be selected as subject, because there is an argument with more proto-agent properties in the transitive construction in (12). That argument cannot be selected as a DO either, because there is an argument (lexicalized as DO in the transitive construction) with proto-patient properties.

The parallelism with passives cannot be pursued with other unaccusatives that lack the transitive counterpart, such as the (only) Spanish corpus example in (14a) or Primus' Italian example in (14b):
a. Al hombre se le caen las gafas.
Spanish, Noc to-the man refl $\mathrm{cl}_{\mathrm{cl}}$ to-him ${ }_{\mathrm{cl}}$ fall the glasses
'The man drops his glasses'
b. Ai bambini non manca energia.
to-the children not lacks energy
Italian, Primus (1999)
'Children do not lack energy'

Nevertheless, the thematic pattern is exactly the same as that of verbs like rompersi: the IO is the possessor, and the subject is the possessed entity, and in (14b) it undergoes a change of state. The subject-IO (or nominative-dative) pattern is therefore typically present when the arguments are in a possessed-possessor relation. ${ }^{17}$

Sbj-IO predicates are also used to avoid mentioning the participant that has control over the event. Consider the (only) Italian example I found in the corpus:

\footnotetext{
${ }^{17}$ Primus proposes an Optimality Theoretic account for nominative-dative predicates. She claims that besides Dowty's Principle, argument selection is determined by constraint rankings. Nom.-dat. predicates result from the high ranking (in German and Romance) of the constraints: (a) Every predicate must have a nominative argument, and (b) A dative argument must have a small number of proto-agent properties.
} 
(15) A un bambino un giorno arriva un regalo.

Italian, Noc to a boy one day arrives a present

'One day a boy receives a present'

The picture the speaker is watching is the first one of the book, depicting a boy looking at a big pack with a bow. The picture does not show who gave the present to the boy.

The construction in (15) allows the speaker not to mention the unknown agent (cf. also Salvi 1988[2001]).

Consider now the choice of topic in these constructions. Given that the subject has proto-patient properties, and the IO has proto-agent properties, we expect the IO to be the preferred topic. Indeed, that is the case. First, subjects of these verbs are frequently post-verbal (cf. Calabrese 1992; Saccon 1993; Pinto 1997 for Italian), so they are not usually topics. A couple of corpus examples are given below:

a. E' arrivato un pacco a casa del bambino.

Italian, Noc is arrived a pack at house of-the boy

'A pack has arrived at the boy's house'

d. De repente, sale la rana. Spanish, Noc of sudden comes-out the frog 'Suddenly the frog comes out'

The IO, on the other hand, is typically used as topic: the constructions in (14) and (15)

(cf. also (11)) are all pragmatically preferable to those with reversed order in (17).
a. Las gafas se le caen al hombre. the glasses refl $\mathrm{cl}_{\mathrm{cl}}$ to-him $\mathrm{cl}_{\mathrm{cl}}$ fall to-the man 'The man's glasses fell out'
b. Energia non manca ai bambini. Italian energy not lacks to-the children 'Children do not lack energy'
c. Un regalo un giorno arriva a un bambino. Italian a present one day arrives to a boy 'One day a boy receives a present' 
Note also that the subjects in (17b) and (17c) lack other prototypical semantic properties. In (17b), energia 'energy' lacks concreteness (recall van Oosten's claim that a prototypical topic is a concrete and visible entity), and violates the preference for a human topic (which could be satisfied by the other argument). Furthermore, recall that a topic expression is an anchor to the common ground, so definite descriptions are better topics than indefinites or bare nouns. The subject in (17b) is a bare noun, while the IO is definite, so the $\mathrm{IO}$ would be a better topic in this respect. As for (17c), both arguments are indefinites; however, if the topic is the boy, the familiarity of that referent is easily accommodated by the context: the sentence is uttered at the beginning of a story, where it is expected that a human or at least an animate protagonist will be introduced. If the topic is the present, on the contrary, its familiarity cannot be easily accommodated.

The IO of an unaccusative verb is a better topic also if it is an inanimate possessor, e.g., when the two arguments are in a part-whole relationship. Consider the sentences below, found after a Google search of se le cae 'it falls out to him/her/it':

a. Al Teatro Español se le cae la cretona. Spanish, Google search to-the theatre Spanish $\mathrm{SE}_{\mathrm{cl}}$ to-it $\mathrm{c}_{\mathrm{cl}}$ falls the cretonne

b. A la trama islamista se le cae el velo. to the plot Islamist $\mathrm{SE}_{\mathrm{cl}}$ to-it $\mathrm{cl}_{\mathrm{cl}}$ falls the veal 'The Islamist plot drops the veal'

The subject refers to a part belonging to the referent of the IO. The preference for an IO topic can be accounted for by van Oosten's distinction between basic-level and subordinate topics. The former are individual participants or elements inside the scene; the latter are an aspect or a part of such elements. A basic level topic is, according to van Oosten, more prototypical than a subordinate topic. In (18a) the cretonne is a component of the theatre, and in (18b), the veal is a (metaphorical) attribute of the 
Islamist plot. Therefore, these referents (if chosen as topics) would be subordinate topics, while the theater and the Islamic plot are basic-level topics. ${ }^{18}$

4.1.3. Passives. As we have already recalled above, the thematic properties of passive constructions are analogous to those of unaccusative verbs. The subject has protopatient properties, and the volitional agent, which is absent in unaccusative verbs, is reduced to an adjunct (the by-phrase) and can be omitted. It follows that a passive is used, like unaccusatives (cf. 15), when the volitional agent is not known by the speaker or is not relevant for the information that the speaker provides.

If a verb selects an IO with proto-agent properties except volition/control, its passive form will display the same sbj-IO pattern seen in the preceding Subsection. Again, the canonical sentence is the one with an IO topic, because the IO is more prototypical than the subject. No examples of passive verbs that select an IO argument were found in the corpus, but see the following example adapted from Salvi (1988[2001]):

(19) A Gianni è stato assegnato un nuovo incarico.

Italian to Gianni is been assigned a new task 'Gianni has been assigned a new task'

Again, if the order of the arguments is reversed, like in (20), the sentence is acceptable only in a context where contrast is expected. For instance, the sentence might be used to point out that a new task has been assigned to Gianni and not to Paolo (contrary to what was previously believed by the participants in the conversation).

\footnotetext{
${ }^{18}$ Note that these sentences are headlines of web pages, so they are not preceded by any linguistic context. It is precisely in cases where previous context is missing that the most prototypical topic is chosen, because there aren't discourse conditions that force a different argument in topic position.
} 
a new task is been assigned to Gianni

'A new task has been assigned to Gianni'

Note that a passive construction does not determine topic selection. The 'promotion' (to use Givón's term) of the DO to subject status does not make it a better topic, given that the (now) subject is still a patient. Of course, if the subject is the only argument of the verb, it is the only choice for topic selection, and may therefore be fronted to a topic position (although it may also remain post-verbal, like most subjects of unaccusative verbs do). But if another argument is present and has proto-agent properties, such as the IO in the examples above, that argument is more likely to be chosen as topic.

It is true that the same preference does not go to the by-phrase representing the volitional agent. A sentence like the one below is rather odd:

Da Piero è stato assegnato un nuovo incarico (a Gianni).

Italian by Piero is been assigned a new task (to Gianni) 'By Piero, a new task has been assigned to Gianni'

However, we may recall that the volitional agent in a passive construction is not an argument, but an adjunct. I argue that this fact excludes it from a first selection of potential topics, and therefore prevents it from being preferred to the IO. As a matter of fact, the function of the passive voice is precisely that of reducing the importance of the volitional agent in the description of the event. In this perspective, it does not make sense that the volitional agent be chosen to express 'what the sentence is about'.

In conclusion, my idea is that a passive construction does not promote the subject to topic position, unless the subject is the only argument of the verb; nevertheless, it does favor a certain choice of topic, as it excludes from topic selection precisely the argument that in the active form would be the topic: the volitional agent. This exclusion 
does not necessarily make the patient subject the best topic: if present, a more agentive object will be preferred by the speaker.

I found 65 passive constructions in the Italian corpus, and only 2 in the Spanish one. Such a strong quantitative difference shows that Spanish prefers a different strategy to avoid mentioning the volitional agent. Specifically, Spanish seems to prefer arbitrary plurals. I will discuss this construction in the following Subsection.

4.1.4. Absence of subject: arbitrary plurals and impersonal verbs. Arbitrary plurals (or arbitrary subjects) are another device that speakers use not to mention the participant that has control over the event described. In this case, the absence of the agent is not due to argument selection. The verb does select a volitional agent (as subject), but that subject is not represented by a full linguistic expression in the sentence, and its referential status is unknown.

As Jaeggli (1986) explains, arbitrary plurals have no phonetic realization in Italian and Spanish, and always appear in tensed clauses as third person plural subjects (cf. also Salvi (1988[2001]). They are always animate and only occur in transitive, unergative intransitive, or raising sentences, which supports the idea that they represent the (volitional) agent in the sentence. I did not find any example in Italian, but I did find 4 examples in Spanish. One is given below:

A nuestro niño protagonista le han hecho un regalo. Spanish, Noc to our boy protagonist to-him $\mathrm{cl}_{\mathrm{t}}$ they-have done a present 'Our protagonist boy received a present'

The context is the same as in (15): the speaker does not know who sent the present to the boy, so she uses a structure that allows her to avoid mentioning the sender. The predicate selects a third argument, the IO, with the proto-agent property of possessor. 
With respect to topic selection, the volitional agent is not eliminated from the argument structure, but still, it is not the most prototypical topic. In fact, referentiality is a prototypical topic property (cf. Subsection 3.1), and in this construction the speaker cannot exactly identify the referent of the subject. It is indeed unlikely that the speaker use a non-identified entity as the topic about which she provides a piece of information, if there are other arguments that can properly carry out that function. Furthermore, an arbitrary subject lacks phonetic visibility, so no linguistic expression would occupy a sentence initial position, and a new, shifting topic (as I assume all topic expressions are) could not be represented by it.

When the only argument besides the arbitrary subject is the proto-patient $\mathrm{DO}$, the sentence is likely to be thetic (all focused), but there are also cases in which the DO is chosen as topic, as in (23):

Y la rana (...) acaba cayendo en una bandeja and the frog ends-up falling in a tray que un camarero por ahí estaba pasando (...). that a waiter for there was carrying-by Entonces este plato lo terminan en la mesa de una señora (...) so this dish $\mathrm{it}_{\mathrm{cl}}$ they-end in the table of a lady 'And the frog (...) ends up falling on a tray that a waiter was carrying by (...). So this dish, they bring it to the table of a lady'

The topic is even inanimate. Interestingly, however, este plato refers to the plate where the frog, the main character of the story, is sitting. Therefore, talking about the plate implies talking about the frog himself and where it is carried. This justifies a patient DO topic.

Other than when they are arbitrary, subjects are absent in a sentence when the verb is impersonal. If the verb selects an IO, it is then likely that it be it that occupies a topic position, as in the (only) Spanish example I found in the corpus: 
Al perro y al niño se les ve muy contentos. Spanish, Noc to-the dog and to-the boy $\mathrm{SE}_{\mathrm{cl}}$ them see very happy

'The dog and the boy look very happy'

In the (only) example I found in the Italian corpus (see 25a), topic selection occurs between the IO and a sentential DO (entrare nell'acqua 'going into the water'), the former being the experiencer of the event described by the latter. The choice again goes to the IO, as shown by the oddness of the reversed order in $(25 \mathrm{~b})$ :

(25) a. Alla mamma gli tocca entrare nell'acqua per recuperare la barchetta. It, Noc to-the mother to-her ${ }_{\mathrm{cl}}$ falls to-go into-the water to retrieve the boat 'The mother has to go into the water to retrieve the boat'

b. Entrare nell'acqua tocca alla mamma. to-go into-the water happens to-the mother

The preference for the IO results clear, given its proto-agent properties. Besides, the mother is a basic-level topic (she is the protagonist of the event), while "going into the water" is the event itself, a superordinate topic, so the former is more prototypical. As for $(25 b)$, a context in which it is acceptable is where the mother is contrasted with other people and/or the event of going into the water is contrasted with other events. Clearly, this kind of contexts is very restricted.

\subsection{Non-canonical sentences with non-subject topics}

In all examples described so far, an argument different from the subject is given topic status by placing it in a preverbal position. This occurs because the referent of the subject would not function as an optimal topic, so the speaker prefers to "talk about" a different referent. In the corpus, 16 out of 40 sentences with non-subject topic can be considered as non-canonical. What triggers the selection of a non-prototypical topic in these sentences? All throughout this article, I have underlined the fact that the 
requirement of a prototypical topic is fulfilled only if discourse factors do not overrule it. In many contexts, that is possible, namely speakers have the freedom to choose different discourse strategies without compromising the understanding of the information they provide and the coherence of their discourse. In such contexts, they will tend to choose the most prototypical topic at their disposal. As I already hinted at various times in this article, the same freedom of choice is not available in other contexts, where the information must be "packed" in a precise way in order for the speaker to convey it successfully. Such contexts require that either the sentence informative part (the focus) be contrasted with a previous piece of information in the discourse, or that the topic itself be contrasted with other topics in the discourse. In the corpus, 11 out 16 non-canonical sentences are used in contrastive contexts. I am now going to discuss such contexts. I will consider first cases of contrastive focus and then of contrastive topic. ${ }^{19}$

\footnotetext{
${ }^{19}$ Of the 5 non-canonical clauses that are not contrastive, 2 can be accounted for by the fact that they have multiple topics: see footnote 21. Two other clauses (an Italian and a Spanish one, depicting the same scene), can instead be explained by the fact that there isn't a great difference between the topic and the other argument in terms of prototypical properties. Consider for instance the Spanish example:

(i) $\mathrm{Y}$ se encuentra que la rana la tiene cogida al brazo. and refl $1_{\mathrm{cl}}$ finds-out that the frog $\mathrm{it}_{\mathrm{cl}}$ she-keeps held at-the arm 'And she finds out that the frog is catching hold of her arm'

La rana (the topic) is the subject of a small clause that constitutes an argument of tener 'to hold'. The difference between la rana and the other potential topic, the subject of tener (the woman who finds the frog catching hold of her arm), is not sharp in terms of prototypical properties: neither is a volitional agent, and the woman has the property of being human, but the frog is the (humanized) protagonist of the story. Furthermore, the woman is a continuous topic, so it is not referred to by a full expression, and that makes the addition of another topic less problematic.
} 
4.2.1. Correction and contrastive focus. A discourse context in which the choice of topic is not free is when the speaker wants to warn the hearer of an incorrect belief or wants to deny the truth of a hearer's belief. If the prototypical argument is part of the information that needs to be contrasted, it cannot be uttered as topic. On the other hand, if the correct information concerns the less prototypical argument, that argument must be the topic. There are two clear cases of this type in the corpus: a Spanish one and an Italian one. Consider the Spanish one first. The frog finds himself in an elegant restaurant, where he frightens everybody with his presence. A woman felt sick after seeing the frog, and is now leaving the restaurant with her husband. The frog is watching the couple leaving (eso 'that' refers to that scene).

La rana los está mirando, feliz, dándose cuenta Spanish, Noc the frog them $\mathrm{cl}_{\mathrm{cl}}$ is watching happy realizing de que eso lo ha hecho ella. of that that $\mathrm{it}_{\mathrm{cl}}$ has done she

'The frog is watching them, happy to realize that HE was the cause of that' The speaker wants to highlight the (pleased) surprise of the frog realizing that he is the cause of the couple's departure. The information of the subordinate sentence (the identification of the individual who caused the couple's departure) is in contrast with the frog's expectations. The subject is in focus because it precisely refers to the individual that contradicts such expectations. Consequently, the DO becomes the only candidate for topic position. Indeed, the DO refers to the scene of the leaving couple, which is precisely what the unexpected information is about.

In the Italian example, the topic is the dislocated DO la punizione 'the punishment':

Insomma, secondo loro, la punizione, stavolta, se la merita. It., Noc in-sum according-to them the punishment this-time refl $\mathrm{cl}_{\mathrm{cl}} \mathrm{i}_{\mathrm{cl}}$ deserves 'In short, for them, this time, he does deserve a punishment' 
The speaker is telling the same restaurant story, and is saying that the boy (the frog's master), according to the boy's parents, deserves a punishment for the disasters caused by the frog. Stavolta 'this time' indicates that the speaker is contrasting this situation with others where the boy had not been punished.

4.2.2. Contrastive topic. Another context that forces the choice of topic is when two pieces of information about two different topics are contrasted. The speaker's goal is to specify what information concerns a topic in contraposition with the information that concerns a different topic. There are several examples in the corpus. Consider (28):

Della cena non gli interessava, Italian, Noc of-the dinner not to-him ${ }_{\mathrm{cl}}$ interested però la rana, poverina, l'aveva quasi persa but the frog poor $\mathrm{it}_{\mathrm{cl}}$ he-had almost lost 'As for the dinner, he didn't care, but the poor frog, he had almost lost it!"

The speaker is telling the restaurant story. A waiter has found the frog and is about to throw it away. The boy owner of the frog recognizes his pet and asks the waiter to give it back to him. The waiter does so but sends the boy and his family away. The speaker says that the boy is sorry, not because the dinner is spoiled, but rather because of the risk he had ran to lose his dear pet. An explicit contrast between the boy's feelings concerning the dinner and those concerning the frog is given. Another example is (29):

Claro esto, la tortuga síque lo vio. of-course this the turtle yes that $\mathrm{it}_{\mathrm{cl}}$ saw

'And the turtle did see that'

The speaker is telling the story about the jealousy of the frog for a younger frog. The frog is told by the boy not to join him and the other pets on a boat, but the frog jumps on it when unseen, and then kicks the younger frog out of the boat. The speaker is contrasting the event of the frog kicking the young frog with the event of the frog 
jumping on the boat. The former was not seen by anybody, but the latter was seen by the turtle. The topic esto 'this one', referri ng to the kicking event, is then contrasted with the previous jumping event.

4.2.3. Multiple topics. Among the non-prototypical topics that I found in my corpus, some occur together with other topic expressions in the same sentence. Lambrecht (1994:148) observes that when a sentence has more than one topic expression, "the point of the utterance is to inform the addressee of the nature of the relation between the referents as arguments in the proposition". ${ }^{20}$ Consider (30). The topic position is occupied by the subject esta 'this one', which is the most prototypical argument, and by the less prototypical IO a mí 'to me'.

(30) Esta a míno me quiere nada bien.

Spanish, Noc this to me no to-me $\mathrm{c}_{\mathrm{cl}}$ want nothing good 'This one does not like me at all'

The sentence is taken from a story about two frogs: a big one and a younger one. The narrator is quoting the young frog. The subject esta 'this one' refers to the big frog. The sentence is about the relation between the big frog and the young frog, and the information is that the former does not like the latter. The prototypical properties of the two topic expressions are not crucial here. What is relevant is whether the relation between the two arguments is the best topic. That is not the case, as such a topic is not a basic level one. The subject, which represents one of the participants of the event and has proto-agent properties, would be a better topic than the relation between the two arguments. So the latter must have been chosen because it was appropriate in the specific context in which the sentence occurred. I would say that in this example, the

\footnotetext{
${ }^{20}$ In fact, the only part in focus is the predicate, and a predicate precisely expresses a relation between its arguments.
} 
context is one where the provided information contrasts against previous expectations, given that there are no apparent reasons for the big frog to hate the young frog.

Most sentences with multiple topics in my corpus occur in contrastive contexts.

Consider the example below.

(31) La rana (...) comincia a guardare le farfalle pure lei.

Italian, Noc the frog begins to watch the butterflies also she

Però la rana, le farfalle se le mangia,e infatti tira fuori la lingua... but the frog the butterflies refl $\mathrm{c}_{\mathrm{cl}}$ them $\mathrm{cl}_{\mathrm{cl}}$ eats and in-fact she-pulls out the tongue 'The frog too begins to watch the butterflies. But the frog EATs butterflies, and in fact, he pulls his tongue out...'

The speaker had previously said that the boy was watching the butterflies, and in (31), he says that the frog is doing the same. The speaker provides some information about the relation between the frog and butterflies, namely that the former usually eats the latter. The speaker is contrasting this relation with the implicitly assumed one between the boy and butterflies (the boy does not usually eat them). So again, the (nonprototypical) topic (the relation between the frog and the butterflies) is justified by the specific (contrastive) context in which it is relevant to talk about it in comparison with the relation between the boy and the butterflies. ${ }^{21}$

\subsection{Canonical sentences and contrast}

Canonical sentences do not have to occur in contrastive or other marked contexts, because the topic expression is chosen by the speaker on the basis of the prototypical properties of its referent. As a matter of fact, most canonical sentences with non-subject

\footnotetext{
${ }^{21}$ It must be further noted that, even when a sentence with multiple topics is not justified by a contrastive context (there are two such cases in the corpus), the non-prototypical topic is made acceptable by the fact that it is associated with a topic that is itself prototypical.
} 
topics in my data occur in unmarked contexts, where the topic is simply a shifting one, and no contrast is implied with other propositions. Among the 9 Italian sentences, none occurs in a contrastive context; among the 15 Spanish ones, 11 are clearly not contrastive.

Nevertheless, the presence of a canonical sentence in a contrastive context does not have to be excluded completely. It may perfectly occur that a prototypical topic, other than being a good topic because of its inherent properties, is also necessary in the discourse to express contrast. A couple of examples are given below:

a. Y a todos parece gustarle, pero a la rana no. Spanish, Noc and to all it-seems to-like-it $\mathrm{cl}_{\mathrm{l}}$ but to the frog not 'And everybody seems to like it, but the frog doesn't'

b. Giovanni e gli altri amici si allontanano e lei rimane da sola. It., Noc Giovanni and the other friends go-away and she remains by herself 'Giovanni and the other friends go away, and she remains alone'

In the sentence with a psych verb in (32a), the feeling of dislike of the frog is contrasted with the opposite feeling of everybody else. In (32b), where the canonical sentence has a topic with the function of subject, the contrast is between the fact that Giovanni and the other friends left while the frog stayed behind.

The difference between canonical and non-canonical sentences then is not given by the possibility to occur in a contrastive context, but by the expectation or not of a contrastive context. While a non-canonical construction clearly signals a contrast effect, a canonical construction does not signal any particular pragmatic effect. The sentence can be used to contrast or correct a previous sentence, but that use is not exclusive.

From this difference between canonical and non-canonical sentences we explain why preverbal subjects and preverbal IOs of psychological and unaccusative verbs are not usually associated with a contrastive interpretation, while CLLDed DOs of 
transitive verbs or subjects of psychological and unaccusative verbs are naturally interpreted as contrastive. Note further that such interpretations are determined by the thematic/semantic characteristics of the arguments in topic position, and are therefore motivated independently from the syntactic positions of the topics.

\section{Conclusions}

In this article I have illustrated the reasons for a non-subject argument to be preferred to the subject as sentence topic. A topic can be prototypical or not, depending on how its thematic/semantic properties reflect humans' preference to talk about certain things and not others. I have called canonical those sentences that have a prototypical topic, and non-canonical those that do not have a prototypical topic. I have shown that canonical sentences with a non-subject topic generally have Sbj-IO predicates (some psychological and unaccusative verbs), where the subject has proto-patient properties, and the IO has proto-agent properties, though it lacks volition/control. Passives, impersonal verbs or predicates with an arbitrary subject may also have a prototypical topic object. Non-canonical sentences, instead, are generally constructions with a CLLDed DO topic. The requirement of a prototypical topic is overruled in these sentences by discourse needs. Precisely, non-canonical sentences are generally used in contrastive contexts: in fact, the need to contrast a certain argument forces it to be focused, and therefore not to be chosen as topic, even if it has prototypical properties. It follows that while a contrastive interpretation of a canonical sentence, although possible, is not expected, a contrastive interpretation of a non-canonical sentence is expected, because it explains the presence of the non-prototypical topic.

\section{References}


Ackerman, Farrell and John Moore (2001). Proto-properties and Grammatical Encoding. A Correspondence Theory of Argument Selection. Stanford, CA: CSLI Publications.

Alsina, Álex (1996). The Role of Argument Structure in Grammar. Evidence from Romance. Stanford, CA: CSLI Publications.

Belletti, Adriana and Luigi Rizzi (1988). Psych verbs and theta-theory. Natural Language and Linguistic Theory 6: 291-352.

Benincà, Paola (1988 [2001]). L'ordine delle parole e le costruzioni marcate. In Grande Grammatica Italiana di Consultazione, Lorenzo Renzi, Giampaolo Salvi, and Anna Cardinaletti (eds.), vol. I, 129-239. Bologna: Il Mulino.

Berman, Ruth A., and Dan. I. Slobin (eds.) (1994). Relating Events in Narrative: A Crosslinguistic Developmental Study. Mahwah, NJ: Lawrence Erlbaum Associates. Brunetti, Lisa (2004). A Unification of Focus. Padua: Unipress.

Brunetti, Lisa (in press-a). On links and tails in Italian. Lingua. doi : 10.1016/j.lingua.2008.10.005.

Brunetti, Lisa (in press-b). Discourse functions of fronted foci in Italian and Spanish. In Focus and Background in Romance Languages, Studies in Language Companion Series, Andreas Dufter and Daniel Jacob (eds.). Amsterdam/Philadelphia : Benjamins.

Calabrese, Andrea (1992). Some Remarks on Focus and Logical Structures in Italian. Harvard Working Papers in Linguistics 1:19-27.

Chafe, Wallace (1976). Givenness, contrastiveness, definiteness, subjects, topics and point of view'. In Subject and Topic, Charles N. Li (ed.), 27-55. New York: Academic Press. 
Dowty, David (1991). Thematic proto-roles and argument selection. Language 67, 3: 547-619.

Duranti, Alessandro and Elinor Ochs (1979). Left-dislocation in Italian conversation. In Syntax and Semantics: Discourse and Syntax. Talmy Givón (ed.), 377-416. New York: Academic Press.

É.Kiss, Katalin (ed.) (1995). Discourse Configurational Languages, Oxford: Oxford University Press.

Fernández Soriano, Olga (1999). Two types of impersonal sentences in Spanish: locative and dative subjects. Syntax 2: 2, 101-140.

Frey, Werner (2004). The grammar-pragmatic interface and the German prefield. Sprache \& Pragmatik 52, 1-39.

Givón, Talmy (1976). Topic, pronoun, and grammatical agreement. In Subject and Topic, Charles N. Li (ed.), 151-188. New York: Academic Press.

Givón, Talmy (1994). The pragmatics of de-transitive voice: Functional and typological aspects of inversion. In Voice and Inversion, Talmy Givón (ed.), 3-46. Amsterdam/Philadelphia: Benjamins.

Hopper, Paul and Sandra A. Thompson (1980). Transitivity in grammar and discourse. Language 56: 251-99.

Jaeggli, Osvaldo A. (1986). Arbitrary plural pronominals. Natural Language and Linguistic Theory 4, 1:43-76.

Kline, Wolfgang and Clive Perdue (1992). Utterance Structure. Developing Grammars Again. Amsterdam/Philadelphia: Benjamins.

Kuno, Susumu (1972). Functional sentence perspective: a case study from Japanese and English. Linguistic Inquiry 3:269-336. 
Kuno, Susumu (1976). Subject, theme, and the speaker's empathy - a reexamination of relativization phenomena. In Subject and Topic, Charles N. Li (ed.), 417-444. New York: Academic Press.

Lambrecht, Knud (1994). Information Structure and Sentence Form. Topic, Focus, and the Mental Representations of Discourse Referents. New York: Cambridge University Press.

Lambrecht, Knud (1995). The pragmatics of case. In On the Relationship between Semantic, Pragmatic, and Grammatical Roles in English and French, Essays in Semantics and Pragmatics, Masayoshi Shibatani and Sandra A. Thompson (eds.), 145-190. Amsterdam: Benjamins.

Lamers, Monique and Helen de Hoop (2005). Animacy information in human sentence processing: an incremental optimization of interpretation approach. In Constraint Solving and Language Processing (Lecture Notes in Artificial Intelligence 3438), Henning Christiansen, Peter Rossen Skadhauge, and Joergen Villadsen (eds.), 158171. Berlin/Heidelberg: Springer-Verlag.

Levin, Beth and Malka Rappaport Hovav (2005). Argument Realization. Cambridge: Cambridge University Press.

Li, Charles N. and Sandra A. Thompson (1976). Subject and topic: A new typology of language. In Subject and Topic, Charles N. Li (ed.), 458-489. New York: Academic Press.

Mac Whinney, Brian (1977). Starting points. Language 53, 1: 152-168.

Masullo, Pascual J. (1993). Two types of quirky subjects: Spanish versus Icelandic. Proceedings of the North East Linguistic Society (NELS) 23: 303-317. 
McNally, Louise (1998). On recent formal analyses of topic. In The Tbilisi Symposium on Language, Logic, and Computation: Selected Papers, Jonathan Ginzburg, Zurab Khasidashvili, Carl Vogel, Jean Jacques Lévy, and Enric Vallduví (eds.), 147-160. Stanford, CA: CSLI Publications.

Murcia-Serra, Jorge (2003). Acquiring the linkage between syntactic, semantic and informational roles in narratives by Spanish learners of German. In Information Structure and the Dynamics of Language Acquisition, Christine Dimroth and Marianne Starren (eds.), 289-309. Philadelphia: Benjamins.

van Oosten, Jeanne (1986). The Nature of Subjects, Topics and Agents: A Cognitive Explanation. Bloomington, IN: Indiana University Linguistics Club.

Pinto, Manuela (1997). Syntax and interpretation of inverted subjects in Italian. PhD dissertation, OTS Utrecht University, Utrecht.

Primus, Beatrice (1999). Cases and Thematic Roles. Ergative, Accusative and Active. Tübingen: Max Niemeyer Verlag.

Prince, Ellen (1992). The ZPG letter: subjects, definiteness and information status. Discourse Description: Diverse Linguistic Analyses of a Fund Raising Text, William C. Mann and Sandra A. Thompson (ed.), 295-325. Philadelphia: Benjamins.

Reinhart, Tanya (1981). Pragmatics and linguistics: and analysis of sentence topics. Philosophica 27, 1: 53-94.

Saccon, Gabriella (1993). Post-verbal subjects. A study based on Italian and its dialects. PhD dissertation, Harvard University, Harvard. 
Salvi, Giampaolo (1988[2001]). La frase semplice._In Grande Grammatica Italiana di Consultazione, Lorenzo Renzi, Giampaolo Salvi, and Anna Cardinaletti (eds.), vol. I, 37-127. Bologna: Il Mulino.

Strawson, Peter (1964). Identifying reference and truth-value. Theoria 30: 96-118, reprinted in Peter Strawson, 1971, Logico-linguistic Papers, 75-95, Methuen.

Strömqvist, Seven and Ludo T. Verhoven (eds.) (2004). Relating Events in Narrative. Vol.2: Typological and Contextual Perspectives. Mahwah, NJ: Lawrence Erlbaum Associate.

Treviño, Esthela (1992). Subjects in Spanish causative constructions. In Romance Languages and Modern Linguistic Theory: Papers from the 20th Linguistic Symposium on Romance Languages, Paul Hirschbühler and Konrad Koerner (eds.), 309-324. Amsterdam: Benjamins.

Vallduví, Enric (1992). The Informational Component. New York: Garland. Vallduví, Enric (1993). Catalan as VOS: evidence from information packaging. In Linguistic Perspectives on the Romance Languages, William J. Ashby, Marianne Mithun, and Giorgio Perissinotto (eds.), 335-350. Philadelphia: Benjamins. Vanhoe, Henk (2002). Aspectos de la sintaxis de los verbos psicológicos en Español. Un análisis léxico funcional. PhD dissertation, Universiteit Gent, Gent. Van Valin, Robert D. Jr. (1990). Semantic Parameters of Split Intransitivity, Language 66: 221-260.

Zubin, David A. (1979). Discourse function of morphology: The focus system in German. In Syntax and Semantics: Discourse and Syntax. Talmy Givón (ed.), 469504. New York: Academic Press. 
Zubizarreta, María Luísa (1999). Las funciones informativas: tema y foco. In Gramática descriptiva de la lengua española, Ignacio Bosque and Violeta Demonte (eds), v. 3, 4215-4244. Madrid: Espasa Calpe. 